\title{
Role of CD11a and CD18 in Diagnosis of Acute Promyelocytic Leukemia
}

\author{
Mona H. Alrayes*, Reham H.M. Hammad*, Enas M. Radwan** and Samar M. Abd El-Hamid* \\ "Department of Clinical Pathology, Faculty of Medicine for Girls, Al-Azhar University and ${ }^{* *}$ Department \\ of Clinical Pathology National Cancer Institute (NCI), Cairo University. \\ Corresponding author: Samar M. Abd El-Hamid, email: drsamar33@yahoo.com
}

\begin{abstract}
:
Background: Acute promyelocytic leukemia (APL) is an aggressive subtype of acute myeloid leukemia (AML) that requires rapid diagnosis and early intervention. Previous studies spotted light on APL being negative for members of $\beta 2$ integrin family CD11a and CD18.

The aim of this work: was to study the value of absence of CD11a and CD18 molecules in screening and its relation to prognosis of APL cases.

Patients and methods: This cross sectional study was conducted on seventy adult ( $>18$ years) patients with de novo AML, recruited from National Cancer Institute, Cairo University. They were divided in to 2 groups; group 1 of APL cases $(n=35)$ and group 2 of AML-Non APL cases $(n=35)$ as a comparative group. Both groups were investigated by flow cytometry for the expression of CD11a and CD18 molecules on leukemic cells.

Results: Comparison between group 1 and group 2 illustrated significant reduction in $\%$ of cells expressing CD11a ( $\mathrm{p}=0.014), \mathrm{CD} 18(\mathrm{p}=0.008)$ and \% of cells co-expressing CD11a /CD18 ( $\mathrm{p}=0.007)$ in group 1 compared to group 2. There was significant positive correlation between $\%$ of cells expressing CD18 and TLC ( $\mathrm{r}=0.411, \mathrm{p}=0.014)$. There was significant positive correlation between CD11a MFI and hepatomegaly $(\mathrm{r}=0.390, \mathrm{p}=0.021)$ in AML-Non APL group. Regarding the output data of ROC curve for discriminative percentage of leukemic cells expressing CD11a and CD18 between APL and Non-APL groups, at cut off $78.95 \%$ and $23.5 \%$ respectively, the specificity for both was $60 \%$ and $68.6 \%$, respectively. While sensitivity was $77.1 \%$ and $68.6 \%$, respectively, with Area Under Curve (AUC) of 0.671 and 0.686 and p value of 0.014 , and 0.008 for leukemic cells expressing CD11a and CD18, respectively.

Conclusion: [1] There is significant reduction in \% of cells expressing CD11a and CD18 in APL patients, but they were neither sensitive nor specific to be used as single markers in diagnosis of APL patients. [2] Positive correlation seen between the most important prognostic factor, TLC and both CD18 MFI and percentage of cells expressing CD18 could throw light on the potentiality of CD18 as a prognostic factor. [3] Significant positive correlation between CD11a MFI and hepatomegaly in Non-APL cases might suggest a role of CD11a in migration of leukemic cells.
\end{abstract}

Keywords: APL, AML, CD11a, CD18.

\section{Introduction:}

Acute promyelocytic leukemia (APL) is an aggressive hematological neoplasm that requires rapid diagnosis and early intervention. APL is characterized by the defining translocation $\mathrm{t}(15 ; 17)$, resulting in the PML: RAR-alpha rearrangement ${ }^{[1]}$. The confirmatory cytogenetic and molecular studies are relatively time-consuming. According to the National Comprehensive Cancer Network (NCCN) Guidelines, ATRA should be started before genetic confirmation in patients with clinical and pathological features of APL, because early initiation of ATRA may prevent the lethal complication of bleeding ${ }^{[2]}$.
The APL is characterized by a highly specific immunophenotyping, which is (CD34CD $117^{+}$HLA-DR $^{-}{ }^{[3]}$. Some of the studies have thrown light on APL being negative for both CD11a and CD18 ${ }^{[4]}$.

Both CD11a and CD18 molecules are members of $\beta 2$ integrin family, and their significance is derived from their exclusive presence in leukocytes ${ }^{[3]}$. CD11a contributes to the strong adhesion and initiation of transendothelial migration. CD18 is involved in many inflammatory and immunological reactions. Mutations of the CD18 result in a profound 
immune deficiency known as LAD-1 (leukocyte adhesion deficiency) ${ }^{[5]}$.

The aim of this work was to study the value of absence of CD11a and CD18 molecules in screening and its relation to prognosis of APL cases.

\section{Patients and Methods}

Our study was approved by the Researches Ethics Committee at Faculty of Medicine, AlAzhar University and Researches Ethics Committee at National Cancer Institute, Cairo University. Informed consents were obtained from all subjects.

This descriptive cross sectional study was conducted on seventy adult ( $>18$ years) patients with de novo AML, recruited from the outpatient clinic of Medical Oncology Department of the National Cancer Institute, Cairo University during the period between October 2016 and March 2018. They were divided in to 2 groups; group 1 of APL cases $(n=35)$ and group 2 of AML-Non APL cases $(n=35)$ as a comparative group.

Inclusion criteria: Patients were included only after being diagnosed with APL or AML-Non APL by immunophenotyping evaluation with multicolor flow cytometer using complete panel of acute leukemia. Samples were considered positive for a marker if $\geq 20 \%$ of cells expressed that marker, except for myeloperoxidase (MPO) $\&$ CD34 positivity was considered $\geq 10 \%$. Molecular study was done using RT-PCR and FISH for presence of $t(15 ; 17)$ to confirm APL diagnosis.

Exclusion criteria: Cases of acute leukemia post chemotherapy treatment and cases of solid malignancies.

All patients in this study were routinely subjected to history taking, clinical examination, abdomenpelvic ultrasound, complete blood count (CBC), bone marrow aspiration (BMA) and immunophenotyping.

\section{Sample collection and preparation:}

Fresh BM samples were obtained on EDTA vacutainers (1-3 ml). BM count was then adjusted to the reference range $\left(1 \times 10^{6} \mathrm{cell} / \mu \mathrm{l}\right)$ before flow cytometric evaluation of the studied markers.

$50 \mu \mathrm{l}$ of adjusted BM sample were placed in two tubes. $\mathbf{1}^{\text {st }}$ tube: was loaded with $5 \mu \mathrm{l}$ of isotype control cocktail IgG1a FITC/IgG2 PE. $2^{\text {nd }}$ tube was loaded with $10 \mu \mathrm{l}$ of each CD11a Fluorescein conjugated antibody. Cat. No: FAB3595F, Clone 345913, mouse IgG1 (R \& D Systems, USA) \& CD18 PE-conjugated antibody. Cat. No: FAB1730P, Clone 21270, mouse IgG1 (R \& D Systems, USA) and incubated in the dark (at $4^{\circ} \mathrm{C}$ ) for 45 minutes. 5 $\mathrm{ml}$ lysing reagent was added to each tube for 3 minutes before centrifugation and finally washed cells were resuspended in 200-400 $\mu \mathrm{L}$ of PBS for flow cytometer acquisition.

\section{Flow cytometry assay}

Flow cytometry assay was conducted in Bone Marrow transplantation Lab, NCI, Cairo University on multicolor Beckman Navious flowcytometry (Clare, Ireland) using system software with a standard 6-colour filter configuration. Acquisition of at least 10,000 events was done for both test and control tubes.

\section{Gating Strategy}

Initial gating was done using typical forwardscatter (FSC) versus side scatter (SSC) on the blast area (A) or classical promyelocytes area (B) or variant M3 (C) or monocytes area (D) (Figure 1). Isotype control of corresponding FITC conjugated IgG1a / PE conjugated IgG2 were used to set up cutoff of positivity for the studied markers. Blast or promyelocytes area evaluated for expression of CD11a and CD18 using quadrant plot where CD11a (FITC) was represented on the $\mathrm{Y}$ - axis and $\mathrm{CD} 18$ (PE) was represented on $\mathrm{X}$-axis. The area of co-expression was manifested in the upper right quadrant, whereas cells negative for both markers were located in lower left quadrant (Figure $2 \mathrm{~A}, \mathrm{~B}, \mathrm{C}$ and D). Single histograms were used for each marker versus count, where the mean fluorescence intensity (MFI) was evaluated in positive population. 


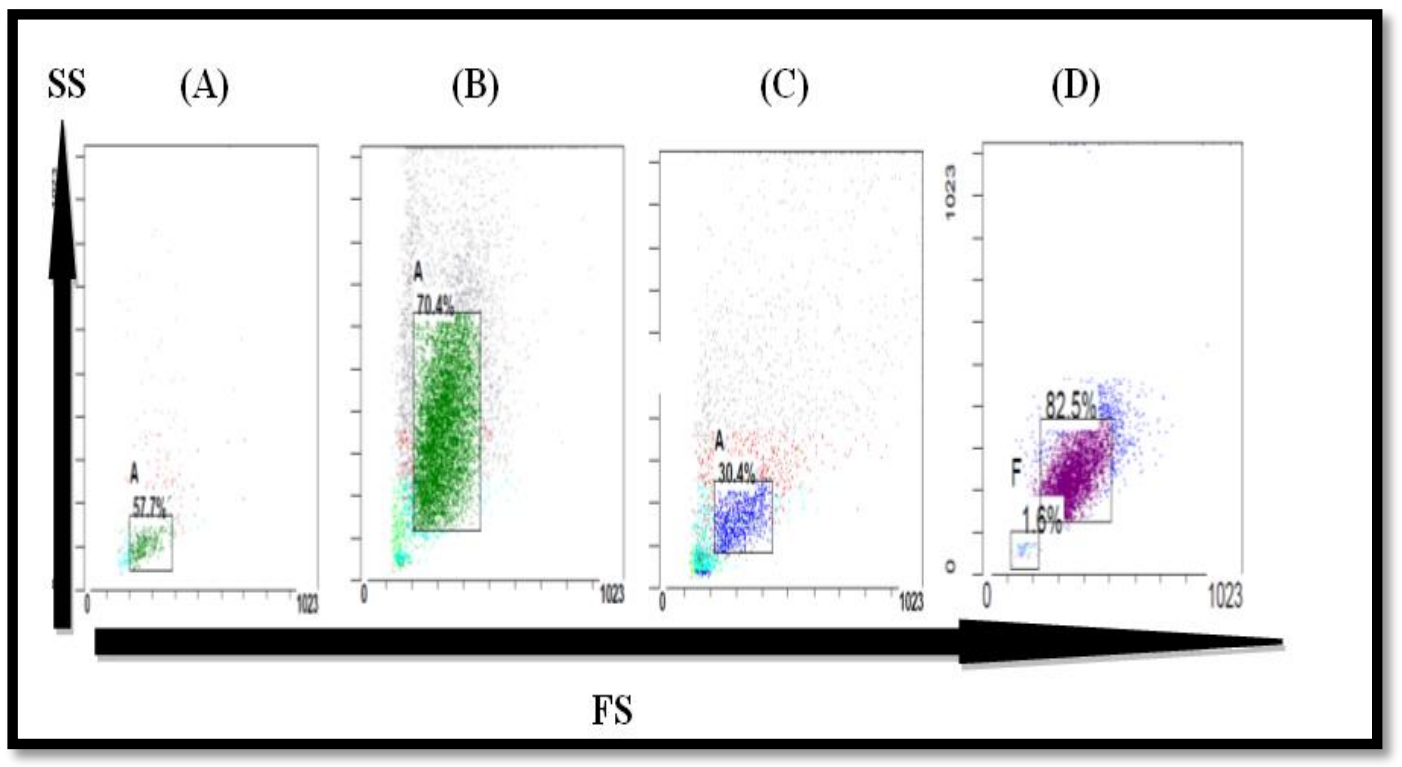

Figure (1): Illustrate FSC /SSC on initial gating area on the classical blast area (A), classical promyelocytes area $(\mathbf{B})$ or variant area $(\mathbf{C})$ or monocytes area (D).

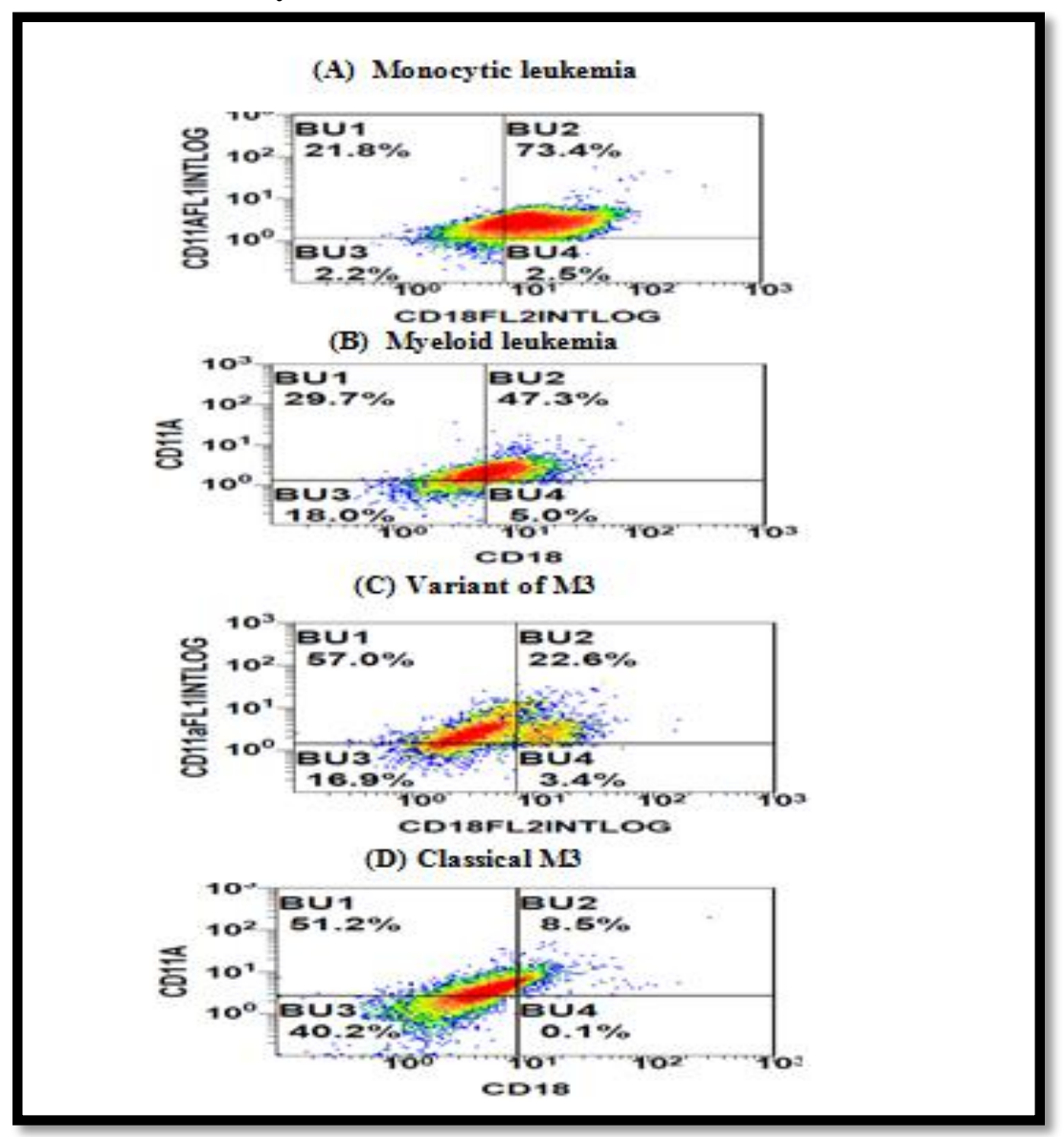

Figure (2): Illustrate quadrant dot plot graph on (A) monocytes blast (B) myelocytes blast, (C) classical M3 (D) and Variant M3. 


\section{Statistical analysis}

Data were coded and entered using the statistical package SPSS (Statistical Package for the Social Sciences) version 25. Data were summarized using mean, standard deviation, median, minimum and maximum in quantitative data and using frequency (count) and relative frequency (percentage) for categorical data. Comparisons between quantitative variables were done using the non-parametric Mann-Whitney test. For comparing categorical data, Chi square $(\chi 2)$ test was performed. Exact test was used instead when the expected frequency is less than 5. Correlations between quantitative variables were done using Spearman correlation coefficient. Survival curves were plotted by the Kaplan-Meier method and compared using the log-rank test. P-values less than 0.05 were considered as statistically significant. Roc curve was done to illustrate deferential cut off of percentage of CD11a, CD18 to discriminate between APL and AML-Non APL.

\section{Results}

Demographic data of the two studied groups was stated in table (1), which illustrated that there is no significant difference between the two groups as regard age and sex.

Descriptive data of group 1 (APL) and group 2 (AML-Non APL) was stated in table (2). Comparison between group 1 and group 2 as regard clinical findings was stated in table (3), which illustrated that there is significant increase in bleeding manifestations in group1 when compared to group $2(\mathrm{p}<0.001)$.

Comparison between group 1 and group 2 as regards blood parameters is stated in table (4). The table illustrated that there is significant increase in; INR $(\mathrm{P}=0.036)$, percentage of leukemic blast/ promyelocytes infiltration of $\mathrm{BM}$ $(\mathrm{P}=0.001), \quad \mathrm{MPO} \% \quad(\mathrm{p}<0.001), \quad \mathrm{CD} 13 \%$ $(\mathrm{p}=0.020)$ and $\mathrm{C} 33 \%(\mathrm{p}<0.001)$, with significant decrease in HLA-DR\% $(\mathrm{P}<0.001)$ in group 1 when compared to group 2 .

Comparison between group 1 and group 2 as regards study parameters is stated in table (5), which illustrated that there is significant reduction in \% of cells expressing CD11a $(\mathrm{p}=$ $0.014), \operatorname{CD} 18(\mathrm{p}=0.008)$ and $\%$ of cells co- expressing CD11a /CD18 ( $\mathrm{p}=0.007)$ in group1 in comparison with group 2.

Group 1 (APL) was subdivided into group 1a: Patients in remission $(\mathrm{n}=13)$ and group 1b: Patients in relapse $(n=22)$. Group 2 (AMLNon APL) was subdivided into group 2a: Patients in remission $(n=10)$ and group $2 b$ : Patients in relapse $(n=25)$.

In APL group, there was significant increase in INR in patients in relapse in comparison to patients in remission $(\mathrm{p}=0.045)$. There was no significant difference between the two groups as regards the study parameters.

In AML-Non APL group, there were significant low values of $\mathrm{LDH}(\mathrm{P}=0.034)$ and INR $(\mathrm{P}=0.041)$ in patients in remission in comparison with patients in relapse.

Correlation studies revealed that there was significant positive correlation between CD11a MFI and CD18 MFI ( $\mathrm{r}=0.558, \mathrm{p}<0.001)$ in APL group. In addition, a significant positive correlation was detected between CD18 MFI and both \% of cells expressing CD18 ( $\mathrm{r}=0.377$, $\mathrm{p}=0.026)$ and TLC $(\mathrm{r}=0.448, \mathrm{p}=0.007)$. While, there was a significant negative correlation with $\%$ of cells expressing CD117 ( $\mathrm{r}=-0.467$, $\mathrm{p}=0.009)$ in APL group. Besides, there was a significant positive correlation between $\%$ of cells expressing CD11a and \% of cells expressing CD18 ( $\mathrm{r}=0.358, \mathrm{p}=0.035$ ) in APL group.

There was significant positive correlation between \% of cells expressing CD18 and TLC ( $r=0.411, p=0.014)$. On the other hand, the \% of cells expressing CD18 is negatively correlated with \% of cells expressing CD117 ( $\mathrm{r}=-0.437$, $\mathrm{p}=0.016$ ) in APL group (Figure 3).

There was significant positive correlation between \% of cells co-expressing CD11a/CD18 and TLC $(r=0.381, p=0.024)$ in APL.

There was a significant positive correlation between CD11a MFI and both CD18 MFI ( $\mathrm{r}=0.448, \mathrm{p}=0.007)$ and $\%$ of cells expressing CD11a ( $\mathrm{r}=0.400, \mathrm{p}=0.017)$. Also, there was a significant positive correlation between CD11a MFI and hepatomegaly $(\mathrm{r}=0.390, \mathrm{p}=0.021)$ in AML-Non APL group.

There was a significant positive correlation between CD18 MFI and \% of cells expressing CD11a $(\mathrm{r}=0.374, \mathrm{p}=0.027), \mathrm{CD} 18$ $(\mathrm{r}=0.727, \mathrm{p}=<0.001)$ and $\%$ of cells co-expressing 
CD11a/CD18 $(r=0.735, \mathrm{p}=<0.001)$ in AML-Non APL group.

There was significant positive correlation between \% of cells expressing CD11a and both \% of cells expressing CD18 ( $\mathrm{r}=0.394, \mathrm{p}=0.019)$ and $\%$ of cells co-expressing CD11a/CD18 ( $\mathrm{r}=0.500$, $\mathrm{p}=0.002)$. On the other hand, the $\%$ of cells expressing CD11a is negatively correlated with $\%$ of cells expressing MPO $(\mathrm{r}=-0.497, \mathrm{p}=0.002)$ in AML-Non APL group.

There was a significant positive correlation between \% of cells expressing CD18 and $\%$ of cells co-expressing CD11a/CD18 $(r=0.984, p=<0.001)$ in AML-Non APL group.

There was significant positive correlation between $\%$ of cells co-expressing CD11a/CD18 and TLC $(r=0.381, p=0.024)$ in AML-Non APL group.

Regarding the output data of ROC curve for discriminative percentage of leukemic cells expressing CD11a and CD18 between APL and Non-APL groups, at cut off $78.95 \%$ and $23.5 \%$ respectively. The specificity for both was $60 \%$ and $68.6 \%$, respectively, while sensitivity was $77.1 \%$ and $68.6 \%$, respectively, with Area Under Curve (AUC) of 0.671 and 0.686 and $\mathrm{p}$ value $=$ 0.014 , and 0.008 for leukemic cells expressing CD11a and CD18 respectively.

Using the Kaplan-Meier curve markers; patients with APL and AML-Non APL with high expression or low expression of the study markers showed no difference in the overall survival.

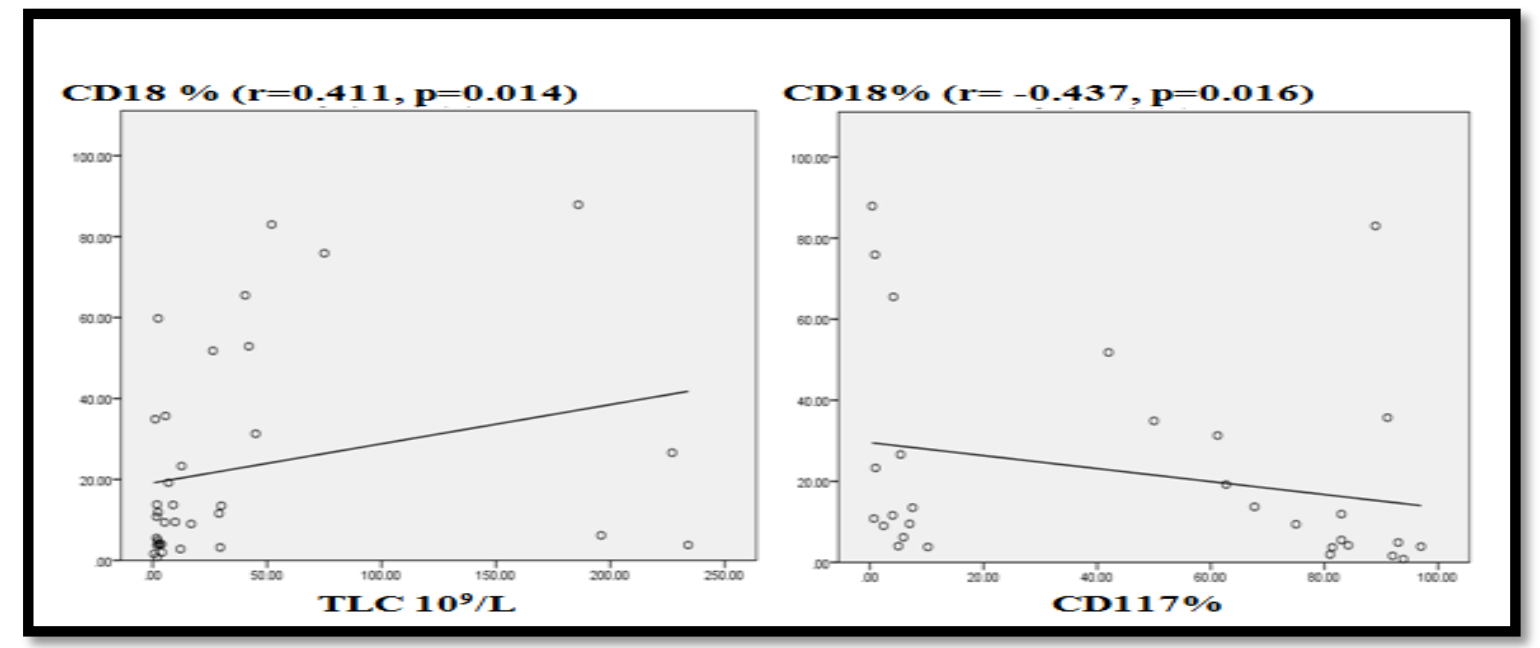

Figure (3): \% of cells expressing CD18 was positively correlated with TLC ( $\mathrm{r}=0.411, \mathrm{p}=0.014)$ and negatively correlated with \% of cells expressing CD117( $r=-0.437, p=0.016)$ in APL group.

Table (1): Demographic data of group 1 and group 2

\begin{tabular}{|c|c|c|c|c|c|}
\hline Item & \multicolumn{2}{|c|}{$\begin{array}{c}\text { Group 1 } \\
\text { (APL) } \\
(\mathbf{n}=\mathbf{3 5}) \\
\end{array}$} & \multicolumn{2}{|c|}{$\begin{array}{c}\text { Group 2 } \\
(\text { AML-Non APL) } \\
(\mathbf{n}=\mathbf{3 5})\end{array}$} & $\begin{array}{c}\text { P value } \\
\text { t: } / \chi^{2}\end{array}$ \\
\hline $\begin{array}{l}\text { Age : (year) } \\
\text { Mean } \pm \text { SD } \\
\text { Median } \\
\text { Range }\end{array}$ & \multicolumn{2}{|c|}{$\begin{array}{c}34.91 \pm 13.08 \\
31 \\
19.00-70.00\end{array}$} & \multicolumn{2}{|c|}{$\begin{array}{c}36 \pm 15.33 \\
32 \\
20-75.00\end{array}$} & 0.769 \\
\hline & No & $\%$ & No & $\%$ & \\
\hline $\begin{array}{l}\text { Sex: } \\
\text { Male } \\
\text { Female }\end{array}$ & $\begin{array}{l}17 \\
18\end{array}$ & $\begin{array}{l}48.6 \% \\
51.4 \%\end{array}$ & $\begin{array}{l}21 \\
14\end{array}$ & $\begin{array}{l}60.0 \% \\
40.0 \%\end{array}$ & 0.337 \\
\hline
\end{tabular}

SD: Stander deviation t: Independent $t$ test $\chi 2$ : Chi Square test $\quad \mathrm{P}>0.05$ is non-significant 
Table (2): Descriptive data of group 1 (APL) and group 2 (AML-Non APL) as regards FAB and cytogenetic results

\begin{tabular}{|c|c|c|c|c|c|}
\hline \multirow[t]{2}{*}{ Item } & & \multicolumn{2}{|c|}{$\underset{(n=35)}{\operatorname{Group} 1(A P L)}$} & \multicolumn{2}{|c|}{$\begin{array}{c}\text { Group } 2 \underset{(n=35)}{(\text { AML }- \text { Non APL) }} \\
\text { (n) }\end{array}$} \\
\hline & & Number & $\%$ & Number & $\%$ \\
\hline \multirow{7}{*}{ Diagnosis } & MO & - & - & 2 & $5.7 \%$ \\
\hline & M1 & - & - & 1 & $2.9 \%$ \\
\hline & M2 & & - & 12 & $34.3 \%$ \\
\hline & M3 & 30 & $85.7 \%$ & - & - \\
\hline & M3v & 5 & $14.3 \%$ & - & - \\
\hline & M4 & - & - & 12 & $34.1 \%$ \\
\hline & M5 & - & - & 1 & $2.9 \%$ \\
\hline \multirow{10}{*}{ Cytogenetic } & $\begin{array}{l}\text { FLT3ITD/TKD835 } \\
\text { Wild type }\end{array}$ & - & - & 5 & $35.7 \%$ \\
\hline & $\begin{array}{l}\text { FLT3-ITD Mutant } \\
\text { (allelic ratio }\end{array}$ & - & - & 1 & $7.1 \%$ \\
\hline & inv.16 & - & - & 2 & $14.3 \%$ \\
\hline & $\begin{array}{c}\text { NPM (Mutant } \\
\text { type)/FLT3 ITD/TKD }\end{array}$ & - & - & 2 & $14.3 \%$ \\
\hline & NPM Wild type & - & - & 1 & $7.1 \%$ \\
\hline & positive PML-RARA & 34 & $97.1 \%$ & - & - \\
\hline & $\begin{array}{c}\text { Positive PML-RARA } \\
\text { /FLT3 TTD/TK } \\
\end{array}$ & 1 & $2.9 \%$ & - & - \\
\hline & t(10;11)(q22;q23) & - & - & 1 & $7.1 \%$ \\
\hline & $\mathbf{t}(9 ; 21)$ & - & - & 1 & $7.1 \%$ \\
\hline & $t(8 ; 21)$ & - & - & 1 & $7.1 \%$ \\
\hline
\end{tabular}

APL: Acute promyelocytic leukemia, AML: Acute myeloid leukemia

Table (3): Comparison between group 1 and group 2 as regards clinical finding

\begin{tabular}{|c|c|c|c|c|c|c|}
\hline \multirow[t]{2}{*}{ Item } & & \multicolumn{2}{|c|}{$\begin{array}{c}\text { Group } 1 \\
(\text { APL) } \\
(\mathbf{n}=35)\end{array}$} & \multicolumn{2}{|c|}{$\begin{array}{c}\text { Group } 2 \\
(\text { AML-Non APL) } \\
(n=35)\end{array}$} & \multirow[t]{2}{*}{$P$ value } \\
\hline & & Number & $\%$ & Number & $\%$ & \\
\hline \multirow{2}{*}{ Bleeding manifestation } & Yes & 19 & $54.3 \%$ & 4 & $11.4 \%$ & \multirow{2}{*}{$<0.001$} \\
\hline & No & 16 & $45.7 \%$ & 31 & $88.6 \%$ & \\
\hline \multirow{2}{*}{ Hepatomegaly } & Yes & 10 & $28.6 \%$ & 14 & $40.0 \%$ & \multirow{2}{*}{0.454} \\
\hline & No & 25 & $71.4 \%$ & 21 & $60.0 \%$ & \\
\hline \multirow{2}{*}{ Splenomegaly } & Yes & 6 & $17.2 \%$ & 11 & $31.5 \%$ & \multirow{2}{*}{0.458} \\
\hline & No & 29 & $82.9 \%$ & 24 & $68.6 \%$ & \\
\hline \multirow{2}{*}{ Lymphadenopathy } & Yes & 2 & $5.7 \%$ & 9 & $25.7 \%$ & \multirow{2}{*}{0.075} \\
\hline & No & 33 & $94.3 \%$ & 26 & $74.3 \%$ & \\
\hline
\end{tabular}

APL: Acute promyelocytic leukemia, AML: Acute myeloid leukemia 
Table (4): Comparison between group 1 and group 2 as regards blood parameters

\begin{tabular}{|c|c|c|c|c|c|c|c|c|c|c|c|}
\hline \multirow[t]{2}{*}{ Item } & \multicolumn{5}{|c|}{$\begin{array}{c}\text { Group } 1 \text { (APL) } \\
(n=35)\end{array}$} & \multicolumn{5}{|c|}{$\begin{array}{c}\text { Group } 2 \text { (AML-Non APL) } \\
(\mathbf{n}=35)\end{array}$} & \multirow{2}{*}{$\begin{array}{c}\mathbf{P} \\
\text { value }\end{array}$} \\
\hline & Mean & SD & $\begin{array}{c}\text { Media } \\
\mathbf{n}\end{array}$ & $\begin{array}{c}\text { Minimu } \\
\mathbf{m}\end{array}$ & $\begin{array}{c}\text { Maximu } \\
\mathbf{m}\end{array}$ & Mean & SD & \begin{tabular}{|c|}
$\begin{array}{c}\text { Media } \\
\text { n }\end{array}$ \\
\end{tabular} & $\begin{array}{c}\text { Minim } \\
\text { um }\end{array}$ & Maximum & \\
\hline Serum U.A mg/dl & 5.72 & 2.86 & 5.10 & 1.90 & 15.60 & 5.87 & 3.91 & 5.50 & 1.70 & 3.60 & 0.865 \\
\hline Serum LDH U/L & $\begin{array}{c}852.5 \\
1\end{array}$ & $\begin{array}{c}1066.3 \\
4\end{array}$ & 645.00 & 169.00 & 6443.00 & $\begin{array}{c}651.8 \\
0\end{array}$ & $\begin{array}{c}429.1 \\
3 \\
\end{array}$ & 498.00 & 243.00 & 1919.00 & 0.537 \\
\hline INR & 1.35 & 0.31 & 1.23 & 1.00 & 2.50 & 1.27 & 0.34 & 1.18 & 1.00 & 2.44 & 0.036 \\
\hline TLC 10 $1 / \mathrm{L}$ & 37.73 & 65.86 & 8.90 & 0.57 & 234.00 & 58.42 & 71.83 & 29.00 & 1.14 & 288.00 & 0.082 \\
\hline $\mathrm{Hb}$ g/dl & 7.97 & 1.55 & 8.00 & 3.00 & 10.30 & 8.08 & 2.22 & 7.80 & 3.40 & 14.40 & 0.805 \\
\hline PIt $10^{9} / \mathrm{L}$ & 34.54 & 24.10 & 24.00 & 5.00 & 3.00 & 52.29 & 55.01 & 31.00 & 10.00 & 277.00 & 0.145 \\
\hline $\begin{array}{c}\text { PB } \\
\text { Blast/promyelocyt } \\
\text { e } \\
\%\end{array}$ & 52.77 & 24.89 & 50.00 & 15.00 & 94.00 & 44.69 & 29.25 & 45.00 & 2.00 & 92.00 & 0.211 \\
\hline $\begin{array}{c}\text { BM } \\
\text { Blast/promyelocyt } \\
\text { e } \\
\% \\
\end{array}$ & 76.17 & 20.39 & 84.00 & 26.00 & 97.00 & 58.11 & 22.87 & 58.00 & 24.00 & 95.00 & 0.001 \\
\hline CD34 \% & 9.3 & 15.12 & 1.70 & 0.10 & 59.00 & 21.90 & 29.61 & 3.30 & 0.04 & 91.00 & 0.297 \\
\hline HLA-DR \% & 6.37 & 14.14 & 2.10 & 0.10 & 76.10 & 50.11 & 32.67 & 53.00 & 1.10 & 96.00 & $\begin{array}{c}< \\
0.001\end{array}$ \\
\hline CD45 \% & 92.74 & 11.56 & 96.25 & 42.00 & 99.90 & 90.34 & 13.82 & 94.50 & 25.00 & 99.50 & 0.294 \\
\hline MPO \% & 80.59 & 16.97 & 84.00 & 42.20 & 99.50 & 50.89 & 28.55 & 57.00 & 0.20 & 99.00 & $\stackrel{<}{0.001}$ \\
\hline CD13 \% & 87.08 & 13.39 & 92.70 & 49.20 & 99.40 & 76.20 & 21.97 & 84.50 & 20.00 & 99.00 & 0.020 \\
\hline CD33 \% & 90.08 & 10.38 & 93.00 & 41.60 & 99.00 & 68.31 & 24.14 & 73.75 & 10.00 & 99.00 & $\stackrel{<}{0.001}$ \\
\hline CD14 \% & 6.13 & 10.08 & 1.02 & 0.10 & 39.00 & 17.43 & 20.86 & 9.56 & 0.10 & 65.00 & 0.282 \\
\hline CD117 \% & 46.06 & 39.16 & 55.60 & 0.40 & 97.00 & 32.74 & 31.69 & 24.00 & 0.10 & 117.00 & 0.269 \\
\hline
\end{tabular}

APL: Acute promyelocytic leukemia, AML: Acute myeloid leukemia, UA: Uric acid, LDH: Lactate dehydrogenase, INR: International Normalization Ratio, TLC: Total leukocyte count, Hb: Hemoglobin, PLT: Platelet count, PB: Peripheral blood, BM: Bone marrow, HLA-DR: Human leukocyte antigen-DR, MPO: Myeloperoxidase.

Table (5): Comparison between group 1 and group 2 as regards study markers

\begin{tabular}{|c|c|c|c|c|c|c|c|c|c|c|c|}
\hline \multirow[t]{2}{*}{ Item } & \multicolumn{5}{|c|}{ Group 1 (APL) $(n=35)$} & \multicolumn{5}{|c|}{ Group 2 (AML-Non APL) $(n=35)$} & \multirow{2}{*}{$\begin{array}{c}\mathbf{P} \\
\text { value }\end{array}$} \\
\hline & Mean & SD & Median & Minimum & Maximum & Mean & SD & Median & Minimum & Maximum & \\
\hline CD11a MFI & 3.63 & 2.63 & 2.93 & 1.09 & 13.70 & 4.09 & 4.09 & 3.18 & 1.21 & 25.40 & 0.634 \\
\hline CD18 MFI & 7.00 & 5.15 & 4.70 & 1.24 & 18.50 & 9.00 & 8.42 & 5.81 & 0.74 & 43.60 & 0.411 \\
\hline CD11a\% & 60.95 & 38.51 & 76.20 & 0.20 & 99.80 & 83.45 & 23.10 & 91.70 & 1.09 & 99.80 & 0.014 \\
\hline CD18\% & 22.79 & 25.47 & 11.60 & 0.80 & 87.90 & 42.26 & 30.85 & 28.00 & 0.60 & 96.00 & 0.008 \\
\hline $\begin{array}{l}\text { Coexpression } \\
\text { of } \\
\text { CD11a/CD18 } \\
\%\end{array}$ & 21.93 & 27.01 & 9.00 & 0.10 & 87.80 & 40.15 & 30.00 & 27.70 & 0.30 & 90.20 & 0.007 \\
\hline
\end{tabular}

APL: Acute promyelocytic leukemia, AML: Acute myeloid leukemia, MFI: Mean fluorescence intensity. 


\section{Discussion}

Flow cytometry is a valuable tool for diagnosis of acute leukemia. Both CD11a and CD18 molecules are members of $\beta 2$ integrin family, and their significance is derived from their exclusive presence in leukocytes ${ }^{[6]}$.

The provisional diagnosis of suspected APL group was based on clinical, PB and BM findings. Flowcytometry immunophenotyping of leukemic cells with absence of CD34 and HLADR expression together with bright expression of CD33, dim to bright expression of CD13, and strong MPO expression were considered characteristic of APL. The diagnosis was confirmed by positivity for $\mathrm{t}(15 ; 17)$ using RTPCR and FISH and only positive cases were included in the current study.

In the current study, the mean age of APL group was $34.91 \pm 13.08$ years old and median value $=31$ years $($ table 1 ). Similar finding was reported by El-Dansory et al. ${ }^{[7]}$. They found that the mean age of APL patients was $34.3 \pm 6.8$ years old. Also, Xu et al. ${ }^{[8]}$ reported that the median age of patients with de novo APL was 31 years old. On the other hand, Horna et al. ${ }^{[9]}$ reported that the median age of APL was 53 years old. This discrepancy could be attributed to ethnic differences between the two studies as the latter study was performed on American population while current study were performed on Egyptian population.

In the present study, the mean age of AMLNon APL group was $36 \pm 15.33$ years old and median value $=32$ years (table, 1). Different values were obtained by El-Dansory et al. ${ }^{[7]}$ who reported that AML-Non APL group had elder mean age of $44.2 \pm 9.5$ years.

At the present work, the male: female ratio was 1:1.05 in M3 group showing nearly equal sex distribution (table, 1). El-Dansory et al. ${ }^{\text {[7] }}$ reported a higher male incidence in APL cases with male to female ratio of 1.5:1 and also Horna et al. ${ }^{[9]}$ reported that the male: female ratio was 1.2:1. The different data among the studies could be due to the variation in sample size and/or geographical factors.

In this study, there was a significant increase of both bleeding manifestations and INR value in APL group when compared to AML-Non APL group $(\mathrm{p}=<0.001 \& \mathrm{P}=0.036$, respectively) (tables 3, 4). Many other studies reported that the
APL patients often suffered from a severe bleeding diathesis and hemorrhagic complications, they referred the hemorrhagic diathesis to multiple causes as; thrombocytopenia, disseminated intravascular coagulopathy (DIC) and systemic fibrinolysis ${ }^{[10]}$.

Many studies explained that the malignant promyelocytes contain large amounts of tissue factor (TF) inside malignant promyelocytes cytoplasmic granules. TF is the principal initiator of the extrinsic coagulation cascade in nonstoppable sequel which leads to consumption of the coagulation factors ${ }^{[11]}$. Moreover, Manthaa et al. ${ }^{[1]}$ reported that microparticles released from promyelocytes in APL expressed TF at their surface which adds to the bleeding acceleration.

Another mechanism of hemorrhage that encountered in APL, is the hyper fibrinolysis mediated by annexin II expressed on the surface of the promyelocytes. Annexin II accelerates the conversion of plasminogen to plasmin ${ }^{[12]}$. It was also reported that, cerebral endothelial cells express annexin II, which explains the high incidence of intracerebral bleeds seen in APL ${ }^{[13]}$.

Dicke et al. ${ }^{[14]}$ reported that in all newly diagnosed AML patients could suffer of coagulopathy regardless the type of AML.

In the current study, the comparison between APL and Non-APL groups as regard hepatomegaly, splenomegaly and lymph nodes (LNs) enlargement showed no significant difference (table, 3). Different findings were obtained by El-Dansory et al. ${ }^{[7]}$. They reported that the frequency of splenomegaly is greater in APL cases than Non-M3 cases and the frequency of lymphadenopathy is less in APL cases than Non-APL cases in their study on AML cases.

The percentage of $\mathrm{BM}$ infiltration with leukemic cells showed a significant increase in APL group when compared to Non-APL group $(\mathrm{p}=0.001)$ (Table, 4). It is worth noticing that the BM of APL cases was packed with leukemic promyelocytes with median value of promyelocytes infiltration $=84.00 \%$, while the median value of TLC in APL cases was $8.90 \times 10^{9} / \mathrm{L}$, which showed no increase in TLC. This high promyelocytes percentage in BM with low TLC was explained by Woz'niak and

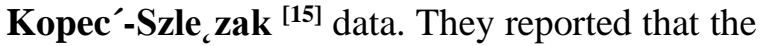
CD117 highly expressed on promyelocytes is 
involved in retaining leukemic cells in the BM and even in stopping their release into $\mathrm{PB}$, which contributes to the relatively low TLC, and that the high density of CD117 may support strong adhesion of leukemic cells to BM stromal fibronectin. Fibronectin in turn inhibits apoptosis and augments the survival of leukemic cells.

In the present work, there was a significant decrease in \% of leukemic cells expressing HLADR in M3 group when compared with Non-M3 group $(\mathrm{p}<0.001)$ (table 4). On the other hand, the expression of CD34 and CD117 showed no significant difference between M3 and Non-M3 groups ( $\mathrm{p}>0.05$ ). Rahman et al. ${ }^{[4]}$ and Zhou et al. ${ }^{[5]}$ documented that APL cells were negative for HLA-DR expression in contrary to other AML types. Liu et al. ${ }^{[3]}$ stated that APL is characterized by being (CD34-CD117+HLADR-) which is useful in distinguishing it from other subtypes of AML.

Comparison between APL and Non-APL groups revealed significant increase in the myeloid markers; MPO\% ( $\mathrm{p}<0.001), \mathrm{CD} 13 \%$ $(\mathrm{p}=0.020)$ and $\mathrm{C} 33 \%(\mathrm{p}<0.001)$ in the $\mathrm{M} 3$ group (table 4). Zhou et al. ${ }^{[5]}$ reported that most of the APL cases showed increased positivity in CD33 and CD13. On the other hand, Rahman et al. ${ }^{\text {[4] }}$ found that APL and Non-APL cases, showed no significant difference in the expression of CD13 and CD33.

In the present study there was significant decrease in percent of cells expressing CD11a, CD18 and \% of cells co-expressing CD11a /CD18 in APL group in comparison to Non-APL group ( $\mathrm{p}=0.014, \mathrm{p}=0.008, \mathrm{p}=0.007)$ respectively (table, 5).

El-Dansory et al. ${ }^{[7]}$ considered that if $20 \%$ of cells expressing either CD11a or CD18 will indicate positivity of the marker. On the other hand, Zhou et al. ${ }^{[5]}$ reported that $20 \%$ was considered as suboptimal cutoff for CD11a\% and $\mathrm{CD} 18 \%$ for APL diagnosis and the distinction between APL and AML of other types. They suggested that the optimal cutoff should be $30 \%$ for both CD11a and CD18 to indicate positivity.

According to that, the results obtained in this study of median values of $\%$ of expression of both CD18 and CD11a/CD18 co-expression were considered as negative expression, while CD11a was considered positive expression using any of the cut offs suggested by El-Dansory et al. ${ }^{[7]}$ or Zhou et al. ${ }^{[5]}$.

Di Noto et al. ${ }^{[16]}$ reported that CD11a was not expressed in most of APL cases. Paietta et al. ${ }^{[17]}$ reported that $75 \%$ of APL cases did not express CD11a. In addition, Rahman et al. ${ }^{[4]}$ found that APL cases characteristically lack the expression of the $\beta 2$ integrin CD11a and CD18. Tang et al. ${ }^{[18]}$ mentioned that APL cases illustrate surrogate surface phenotype of HLA$\mathrm{DR}^{\text {low }}, \mathrm{CD} 11 \mathrm{a}^{\text {low }}$ and CD18 $18^{\text {low }}$ by flow cytometry. Wu et al. ${ }^{[19]}$ described that APL cases lack CD11a expression before receiving ATRA therapy, while APL cases post-ATRA therapy are capable of acquiring $\beta 2$ integrin on the cell surface either during maturation in the $\mathrm{BM}$ or following egress into the $\mathrm{PB}$. The discrepancy among the results reported in the literatures might be due to differences in the specificity and/or sensitivity of the monoclonal used in the detection. Besides, the number of the studied patients might be considered.

Group 1 of APL cases $(n=35)$ was subdivided according to ATRA treatment outcome into patients in remission; group 1a $(n=13)$ and patients in relapse group $1 b(n=22)$. The comparison between both groups revealed no significant differences as regards the clinical findings and the study markers.

The APL patients in relapse showed significant increase in INR in comparison with APL patients in remission ( $\mathrm{p}=0.045)$. This was in agreement with Mantha et al. ${ }^{[1]}$ who reported that coagulopathy is associated with early death and failure of ATRA therapy induction with increased incidence of relapse as ATRA has incomplete effect on hyper fibrinolysis state in APL patients.

Group 2 of AML-Non APL cases was subdivided according to treatment outcome to patients in remission group $2 \mathrm{a} \quad(\mathrm{n}=10)$ and patients in relapse group $2 b(n=25)$. Comparison between both groups revealed no significant differences in the clinical findings or the study markers. There was significant decrease of LDH in remission patients in comparison with patients in relapse. This was in agreement with HU et al. [20] who reported that LDH levels were significantly increased in acute leukemia at relapse compared with patients achieving complete remission. Also, Dowling et al. [21] 
reported that $\mathrm{LDH}$ have a strong correlation between disease activity and tumor mass.

The present study showed that in AML-Non APL group there was significant decrease of INR in patients in remission in comparison with patients in relapse. This was in agreement with Dicke et al. ${ }^{[14]}$ who reported that the systemic coagulopathy resolved during phases of AML remission, but recurred simultaneously with fulminant AML relapse, suggesting that the procoagulant phenotype of myeloblasts may be preserved despite intensive anti-leukemic therapy.

There was no significant difference between APL patients in remission and APL patients in relapse as regards the study parameters. These findings could suggest that, there was no participation of CD11a and CD18 in the clinical outcome in APL group. Similar finding were seen in AML-Non APL group.

In this study, APL group showed significant positive correlation between the density of CD11a MFI on leukemic cells and both the density of CD18 MFI $(r=0.558, p<0.001)$ and $\%$ of cells expressing CD45 ( $\mathrm{r}=0.358, \mathrm{p}=0.044)$. The APL group showed significant positive correlation between the density of CD18 MFI on leukemic cells and \% of cells expressing CD18 $(\mathrm{p}=0.026)$.

In this work all of $\%$ of leukemic cells expressing CD18, CD18 MFI and \% of leukemic cells co-expressing CD11a/CD18 were positively correlated with TLC in APL patients $(\mathrm{p}=0.014, \mathrm{p}=0.007 \& \mathrm{p}=0.024$ respectively). These finding might throw light on the prognostic value of CD18 in APL cases. Many studies conducted on APL patients confirmed the prognostic importance of TLC at diagnosis for impact in risk stratification and clinical management [8 \& 22]. Previous studies proved that elevated TLC is one of the parameters reported to predict severe hemorrhage or hemorrhagic death in APL patients. TLC before treatment was found to be the only independent risk factor of early death, complete remission failure, and five-year mortality rate ${ }^{[8]}$.

Also Testa and Lo-Coco ${ }^{[22]}$ reported that TLC at diagnosis represents the only factor influencing APL outcome in patients receiving ATRA and to stratify the risk groups of APL.
On the other hand, in APL group \% of leukemic cells expressing CD18 and CD18 MFI were negatively correlated with $\%$ of leukemic cells expressing CD117 ( $\mathrm{p}=0.016$ \& $\mathrm{p}=0.009$, respectively). This may connect $\mathrm{CD} 18$ to maturity staging as CD117 is an immaturity marker and it was reported that CD117 density of expression correlates with the stage of maturation [23].

In AML-Non APL group, there was significant positive correlation between CD11a MFI and hepatomegaly $(r=0.390, p=0.021)$. This was in agreement with Coombe et al. ${ }^{[24]}$ who reported that $\mathrm{CD} 11 \mathrm{a} / \mathrm{CD} 18$ is one of the main adhesion molecules used by immune cells to infiltrate the liver under inflammatory conditions. The early metastasis of the tumor cells into a secondary organ, might be due to the up regulation of adhesion molecules expression.

As mentioned CD11a and CD18 are of $\beta 2$ integrin family, Desgrosellier and Cheresh ${ }^{[25]}$; Bendas and Borsig ${ }^{[26]}$ reported that integrin expressed in tumor cells contribute to tumor progression and metastasis by increasing tumor cell migration, invasion, proliferation and survival.

At the best selected cut off levels for $\%$ of leukemic cells expressing CD11a (78.95\%), \% of leukemic cells expressing CD18 (23.5\%) and for $\%$ of leukemic cells co-expressing CD11a/CD18 (13.05\%), these markers showed low sensitivity and specificity to discriminate APL from Non-APL cases.

Zhou et al. ${ }^{[5]}$ reported that; single marker analysis lacked specificity because CD11a, CD18 or HLA-DR were absent in Non-APL cases.

At the end of the present study by using the Kaplan-Meier method patients showing high expression and low expression of study markers in APL or Non-APL; showed no difference in the overall survival.

\section{Conclusion}

[1] Although there is significant reduction in \% of leukemic cells expressing CD11a and CD18 in APL patients, these markers were neither sensitive nor specific to be used as single markers in diagnosis of APL patients. [2] Positive correlation seen between the TLC and both CD18 MFI and percentage of cells expressing CD18 could throw light on the potentiality of CD18 as 
a prognostic factor. [3] The significant positive correlation between CD11a MFI and hepatomegaly in Non-APL cases may suggest a role for CD11a in migration of leukemic cells.

\section{References:}

1. Manthaa S, Tallmanb MS, Devlinc SM, Soffa GA (2018): Predictive factors of fatal bleeding in acute promyelocytic leukemia. Thrombosis Research, 164:S98-S102.

2. Mendoza AS, Qing X, Dungo M, Lasky J, Panosyan E, Cai J (2016): HLA-DR antigen-positive acute promyelocytic leukemia. Experimental and Molecular Pathology, 101: 197-200.

3. Liu M, Weng X, Gong S, Chen H, Ding J, Guo M et al. (2017): Flow cytometric analysis of CD64 expression pattern and density in the diagnosis of acute promyelocytic leukemia: a multi-center study in Shanghai, China. Oncotarget, 8(46): 80625-80637.

4. Rahman K, Gupta R, Singh MK, Sarkar MK, Gupta A, Nityanand S (2017) : The triple-negative (CD34-/ HLA-DR-/CD11b-) profile rapidly and specifically identifies an acute promyelocytic leukemia. Int. J. Lab. Hem., 2017: 1-8.

5. Zhou Y, Jorgensen JL, Wang SA, Ravandi F, Cortes J, Kantarjian HM et al. (2012): Usefulness of CD11a and CD18 in flowcytometric immunophenotypic analysis for diagnosis of acute promyelocytic leukemia. Am. J. Clin. Pathol., 138: 744-750.

6. Reina M, Espe E (2017): Role of LFA-1 and ICAM-1 in Cancer. Cancers, 9: 153.

7. El Danasoury AM, Saad El Dein AA, Al-Feky MA, Ezzat SM, Sallam MT, Kamal GM et al. (2015): Value of CD11a and CD18 in flow cytometric immunophenotypic diagnosis of acute promyelocytic leukemia. Journal of Applied Hematology, 6 (1):9-26.

8. Xu F, Yin CX, Wang CL, Jiang XJ, Jiang L, Wang ZX et al. (2014): Immunophenotypes and immune markers associated with acute promyelocytic leukemia Prognosis. Disease Markers, 2014: 421-906.

9. Horna P, Zhang L, Sotomayor EM, Lancet JE, Moscinski LC (2014): Diagnostic immunophenotype of acute promyelocytic leukemia before and early during therapy with all-trans retinoic acid. Am. J. Clin. Pathol., 142(4): 546-52.

10. Borowska A, Stelmaszczyk-Emmel A, Pawelec K (2016): Central nervous system haemorrhage causing early death in acute promyelocytic leukaemia .Eur. J. Immunol., 40(4): 486-488.

11. Kamikubo Y, Mendolicchio GL, Zampolli A, Marchese P, Rothmeier AS, Orje JN et al. (2017): Selective factor VIII activation by the tissue factorfactor VIIa factor Xa complex . Blood, 130 (14): 1661-1670.

12. Ikezoe $T$ (2014): Pathogenesis of disseminated intravascular coagulation in patients with acute promyelocytic leukemia, and its treatment using recombinant human soluble thrombomodulin. Int. J. Hematol., 100: 27-37.

13. Lad D, Jain A, Varma S (2017): Complications and management of coagulation disorders in leukemia patients. Blood and Lymphatic Cancer: Targets and Therapy, 7: 61-72.

14. Dicke C, Amirkhosravi A, Spath B, Jiménez-Alcázar M, Fuchs T, Davila $M$ et al. (2015): Tissue factor dependent and independent pathways of systemic coagulation activation in acute myeloid leukemia: Exp. Hematology Oncology, 4: 22.

15. Woz'niak J, Kopec'-Szle zak J (2004): C-Kit Receptor (CD117) Expression on Myeloblasts and White Blood Cell Counts in Acute Myeloid Leukemia. Cytometry Part B (Clinical Cytometry), 58B: 9-16.

16. Di Noto R, Lo Pardo C, Schiavone EM, Ferrara F, Manzo C, Vacca C et al. (1996): All-trans retinoic acid (ATRA) and the regulation of adhesion molecules in acute myeloid leukemia. Leuk. Lymphoma, 21: 201-209.

17. Paietta E, Goloubeva O, Neuberg D, Bennett JM, Gallagher R, Racevskis J 
et al. (2004): A surrogate marker profile for PML/RAR alpha expressing acute promyelocytic leukemia and the association of immunophenotypic markers with morphologic and molecular subtypes. Cytometry B Clin. Cytom., 59 (1): $1-9$.

18. Tang G, Truong F, Fadare O, Woda B, Wang SA (2008): Diagnostic challenges related to myeloid/natural killer cells, a variant of myeloblasts. Int. J. Clin. Exp. Pathol., 1(6): 544-9.

19. Wu JJ, Cantor A, Moscinski LC (2007): $\beta 2$ Integrin are characteristically absent in acute promyelocytic leukemia and rapidly upregulated in vivo upon differentiation with all-trans retinoic acid. Leukemia Research, 31: 49-57.

20. Hu W, Wang $X$, Yang $R$ (2016): Evaluation of D-dimer and lactate dehydrogenase plasma levels in patients with relapsed acute leukemia. Oncology Letters, 12: 591-596.

21. Dowling P, Pollard D, Larkin A, Henry M, Meleady P, Gately K et al. (2015): Abnormal levels of heterogeneous nuclear ribonucleoprotein A2B1 (hnRNPA2B1) in tumour tissue and blood samples from patients diagnosed with lung cancer. Mol. Biosyst., 11 (3): 743-752.

22. Testa U, Lo-Coco F (2016): Prognostic factors in acute promyelocytic leukemia: strategies to define high-risk patients. Ann. Hematology, 95: 673-680.

23. Paietta E (2003): Expression of cell surface antigens in APL. Best Practice \& Research Clinical Hematology, 16 (3): 369-385.

24. Coombe DR, Wai Wong C, Dye DE (2012): The role of immunoglobulin superfamily cell adhesion molecules in cancer metastasis. Int. J. Cell Biol.,2012: 340-396.

25. Desgrosellier Js, Cheresh DA (2010): Integrins in cancer: biological implications and therapeutic opportunities. Nat Rev Cancer, 10(1): 922.

26. Bendas G, Borsig L (2012): Cancer Cell Adhesion and Metastasis: Selectins, Integrins, and the Inhibitory Potential of Heparins. International Journal of Cell Biology, 2012: 5-7. 